\title{
Fit or Fitting In: Deciding Against Normal When Reproducing the
}

\section{Future}

Roxanne Mykitiuk

Osgoode Hall Law School of York University, rmykitiuk@osgoode.yorku.ca

Isabel Karpin

Source Publication:

Continuum: Journal of Media and Cultural Studies 31:3 (2017) pp. 341-351

Follow this and additional works at: https://digitalcommons.osgoode.yorku.ca/scholarly_works

Part of the Law Commons

\section{Repository Citation}

Mykitiuk, Roxanne and Karpin, Isabel, "Fit or Fitting In: Deciding Against Normal When Reproducing the Future" (2017). Articles \& Book Chapters. 2552.

https://digitalcommons.osgoode.yorku.ca/scholarly_works/2552

This Article is brought to you for free and open access by the Faculty Scholarship at Osgoode Digital Commons. It has been accepted for inclusion in Articles \& Book Chapters by an authorized administrator of Osgoode Digital Commons. 


\title{
Fit or Fitting in: Deciding Against Normal When Reproducing the
}

\section{Future}

\author{
Roxanne Mykitiuk ${ }^{a} \&$ Isabel Karpin ${ }^{b}$
}

a Osgoode Hall Law School, York University, Canada ${ }^{b}$ Faculty of Law, University of Technology, Sydney, Australia

Corresponding author: Isabel.Karpin@uts.edu.au, Faculty of Law, University of

Technology Sydney PO Box 123 Broadway, 2007

$\underline{\text { Ph: }+61295143179}$

\section{Notes On Contributors}

Roxanne Mykitiuk is an Associate Professor and Director of the Disability Law Intensive clinical program at Osgoode Hall Law School, York University. She was Senior Legal Researcher for the Canadian Royal Commission on New Reproductive Technologies; a member of the Ontario, Advisory Committee on Genetics; a member of the Ethics Committee of the Society of Obstetricians and Gynecologists of Canada and scholar in residence at the Law Commission of Ontario working on the Disability and Law Project. Roxanne is the author or co-author of numerous articles, book chapters and books investigating the legal, ethical and social implications of reproductive and genetic technologies and the legal construction and regulation of embodiment and disability. Her current research projects are funded by CIHR, SSHRC, the Australian Research Council and the European Research Council.

Isabel Karpin is a Professor in the Faculty of Law at the University of Technology Sydney. She researches on the bioethical implications of laws governing reproductive technologies, genetic testing and disability. She explores the challenge posed by new biotechnological developments on legal understandings of normality, disability, individuality, and family. Professor Karpin is the author and co-author of articles, book chapters and books including recently Perfecting Pregnancy: Law Disability and the Future of Reproduction 2012 (with K Savell) published by Cambridge University Press and edited collections such as Nisker, Baylis, Karpin, McLeod and Mykitiuk "The Healthy Embryo" (Cambridge 2010). She is currently involved in two major Australian Research Council projects, one exploring the regulation of behaviour as a disability and the other examining family formation using reproductive technology both inside and outside law and across borders. 


\section{Disclosure statement}

No potential conflict of interest was reported by the authors.

\section{Acknowledgement}

This article is funded by ARC DP 15010157 Regulating Relations: Forming Families Inside and Outside Laws Reach. The authors wish to thank their coinvestigators Professors Jenni Millbank and Anita Stuhmcke from the University of Technology Sydney and Emily Jackson from London School of Economics. We would also like to thank Michaela Stockey-Bridge, Miranda Kaye and Odelia Bay for their research assistance. 


\title{
Fit or Fitting in: Deciding Against Normal When Reproducing the Future
}

\begin{abstract}
'Normal' is a contentious term. Descriptively, 'normal' is a way of representing 'what is' as a statistical average. The term also represents normative or prescriptive content about what is 'right' or 'what should be'. Correspondingly, abnormality is a deviation from the norm. It is both a factual exception to the average and a value judgment about what is a 'wrong' state of being. Pursuing 'normal' or deciding against it can be a defining moment in the high technology environment of assisted reproduction. In this article we explore notions of normalcy articulated through legal and policy regimes around screening and testing of gamete and embryo donors. To do this we draw on the work of disability scholars and the diversity of responses to the idea of normal that were registered by four women interviewed in studies undertaken by the authors. Three of the interviewees had used or were intending to use donated gametes and the fourth had intended to donate her embryos. We demonstrate how the choice of a particular donor may reveal ingrained or structural prejudice that reconstructs difference as disability. Equally, however, it may reveal a multitude of ways in which difference or deviation from a normative standard is incorporated as a normal part of family formation.
\end{abstract}

Key words: normal, abnormal, disability, donated gametes, donated embryos, donors

\section{Introduction}

'Normal' is a contentious term. Descriptively, 'normal' is a way of representing 'what is' as a statistical average, however the term also represents normative or prescriptive content about what is 'right' or 'what should be'. Correspondingly, abnormality is a 
deviation from the norm. It is both a factual exception to the average and a value judgment about what is a 'wrong' state of being (Taylor and Mykitiuk, 2001). Pursuing 'normal' or deciding against it can be a defining moment in the high technology environment of assisted reproduction. In this article we explore notions of normalcy articulated through legal and policy regimes regarding screening and testing of gamete and embryo donors. To do this we draw on the work of disability scholars and the diversity of responses to the idea of normal that were registered by four women interviewed in studies undertaken by the authors. (ARC DP 986213: Enhancing Reproductive Opportunity 2009-2013 and ARC DP 15010157: Regulating Relations 20152018). Three of the women were interviewed because they had used, or were intending to use, donated gametes and the fourth had intended to donate her embryos. All four had encounters with donor selection systems and genetic testing regimes. Our research suggests that in some cases the choice of a particular donor may reveal ingrained or structural prejudice that reconstructs difference as abnormality. Equally, however, it may reveal a multitude of ways in which difference or deviation from a normative standard is incorporated as a normal part of family formation.

\section{Screening and testing protocols for donated gametes}

ART clinic testing and screening protocols for donors exist to ensure they and/or their gametes are unaffected by genetic anomaly, infectious disease or psychological illness and are often more rigorous than for people who reproduce with ART using their own gametes. These guidelines and practices reflect a conception of what, in the clinical context, is considered to be 'normal' in both the descriptive and prescriptive sense, while at the same time, arguably, prescribing more than the usual indicators for what is traditionally understood as good health. Nevertheless, screening and testing practices vary quite markedly across clinics and jurisdictions suggesting that there is no clear consensus about what constitutes a 'normal' or 'healthy' donor or donated gamete.

Australian clinics have both a domestic and imported supply of gametes for reproductive use and must comply with the Australian Reproductive Technology Accreditation Committee Code of Practice, the National Health and Medical Research Council guidelines on Assisted Reproduction and State based legislation. Apart from standard disease transmission controls there are no specific requirements regarding testing or screening though most clinics have extensive screening and testing regimes. IVF Australia, for instance, tests sperm donors' chromosomes and for genetic conditions such as cystic fibrosis, sickle cell disease, and other conditions depending on ethnic background (http://www.ivf.com.au/fertility-treatment/donor-program/require-asperm-donor). In the United States, the UK, and Europe a range of protocols and regulations operate for donated gametes. In Europe, for instance, under the European Union Directive on Human Tissues and Cells, 'gamete donors should be screened (tested) "for autosomal recessive genes known to be prevalent (...) in the donor's ethnic background"' (Dondorp et al. 2014, 2; Commission Directive 2006). In the US, screening and testing for certain autosomal conditions is recommended by the American Society for Reproductive Medicine (ASRM) regardless of ethnicity for the entire population, 
including carrier testing for Spinal Muscular Atrophy (Prior 2008 cited in Dondorp et al 2014, 1355) and Cystic Fibrosis (ACOG 2011). While, the ASRM do not require karyotyping for chromosomal translocations, the French Centre d'Etude et de Conservation des Oeufs et du Sperme Humains and British guidelines of the Association of Biomedical Andrologists (Dondorp et al. 2014) recommend it. In comparison, in Germany and the Netherlands there is an active recommendation against karyotyping (Dondorp et al. 2014). Finally, some protocols go so far as to recommend against using a donor who tests positive as a carrier for a heterozygous autosomal recessive disorder (requiring two copies of the gene for the disorder to materialize) (Dondorp et al. 2014). This is despite the fact that, as Sara Wienke et al., report, '[i]t is estimated that each individual is a carrier of between zero and seven severe childhood recessive conditions with an average of 2.8 found in one study' $(2014,191)$. This has led McGowan, Cho, and Sharp to suggest that 'identification as a carrier [is] the new normal' $(2013,9)$.

From this brief summary it is apparent that there is no consensus about testing/ screening protocols for donated gametes. Rather, they reflect a range of views about what constitutes a 'normal' or 'healthy' gamete. In the United States, where there is a commercial market for gametes, preconception screening and testing of donors is comprehensive. The World Egg Bank for instance, advertises next generation massive sequencing (NGS) which they describe as 'a powerful new technology that can examine the entire genetic code of a female donor, and predict how her DNA, or genetic code, will interact with the genetic information of the male partner before conception.'

(http://www.theworldeggbank.com/next-generation-testing/). Testing is not limited to genetic analysis, but often includes comprehensive psychological testing alongside analysis of the medical history of the donor's immediate family (parents, grandparents and siblings) including any familial experience of conditions such as depression, mood swings, anxiety, and more. Though not required by any professional guidelines, a number of US IVF clinics use personality tests when screening potential donors. One clinic, the New York University Fertility Centre, has undertaken a study of its own practices using what they called 'enhanced genetic and psychological testing,' and reported excluding 31 percent of potential donors based on genetic and psychological factors. The report states: 'Enhanced genetic screening with universal testing for TaySachs, Fragile X and karyotype excluded 25 candidates' (Reh et al. 2010, 2300). However it goes on to say '....those excluded for a personal or family medical history had histories suggestive of an unacceptable transmissible genetic trait such as dyslexia, early cardiac disease and aggressive cancers' (2300). These potential candidates were not identified (and excluded) by genetic testing but based on family histories. Further, exclusions occurred based on what was described as 'basic psychological screening.' Reh notes that 'depression was the most common factor for exclusion and alcoholism was the most common factor identified in family history of psychological disorder' (2300). But people were also excluded for attention deficit disorder, obsessive-compulsive disorder, family history of schizophrenia, suicide, bipolar disorder and other conditions (2302). Enhanced psychological testing where even more candidates were excluded for 'unfavourable behaviour' followed this including for: dishonesty, non-compliance, immaturity, criminal history, hostility toward staff and refusal to disclose donation to spouse. 
The testing and screening practices described above suggest an acceptance of the heritability of not only single gene conditions but of complex psychological conditions and socially undesirable personal characteristics as well as those regarded to be desirable. Daniels and Heidt-Forsythe equate this geneticization with a modern eugenics movement and state: 'The belief that idealized (and often nonbiological) human traits are transmitted genetically is one historical characteristic of the eugenics movement and....[w]e argue that sperm and egg donation practices in the American reproductive industry mirror positive eugenic beliefs in new and more subtle forms' (Daniels and Heidt-Forsythe 2012, 720). However, if these screening and testing processes are in lock step with an ideology of improvement it is by no means clear, as our research demonstrates below, that the people who access them have a shared understanding of what is 'better' or indeed what is 'normal'.

\section{Diverse normality and normal disability}

In The End of Normal, Lennard Davis describes 'diversity' as the new normal but as a constrained concept (Davis 2013) under conditions of neoliberalism. As a neoliberal concept, Davis argues, diversity is shaped by a commitment to the self-authorizing individual and 'implies celebration, choice'(8) and malleability (5). However, disabled bodies are conventionally imagined as 'fixed' $(6,7)$, in need of fixing and an identity that is not chosen (by oneself or others) $(11,14)$. Thus, for Davis, the neo-liberal diverse subject, cannot incorporate disability. This caveat is an important corrective to an uncritical embrace of the concept of diversity among those who might otherwise see it as a means to achieve radical inclusion. Davis states 'the concept of diversity, currently is rendered operative largely by excluding groups that might be thought of as abject or hypermarginalised' (4). Disability, therefore, 'reveals the state of exception' in the neoliberal diversity paradigm, 'by being continuously connected with the exception to the norm.'(9). Thus, Davis' contention is that the very difference of disability - its abjectness, immutability and unchoseness - is the necessary category of the not normal against which a self-chosen and malleable diversity can be inscribed as normative (14).

We suggest, and our research demonstrates below, that within the context of ART, where a neoliberal consumerist model increasingly proliferates, diversity nevertheless has a more expansive meaning than that suggested by Davis. We have found that some users of ART re/construct disability within a more capacious and diverse understanding of normalcy - what we might call diverse normality. Indeed, for some users of ART, a neo-liberal construction of diversity is neither accepted nor desired.

The idea that disability can be regarded as 'a new normal' has been proposed by Ginsburg and Rapp (2016). On their account, the increased growth of the (American) population with disabilities and its projected rise in the future, signals an opportunity for 'a refiguring of notions of typicality that we think of as "a new normal" in which the inclusion of disability is no longer considered exceptional but is simply taken for granted....' (2016). Integral to this shift to a 'new normal' are the requisite accommodations of disability together with accessible and inclusive futures in which 
persons with a panoply of disabilities are accommodated as full participants.

As we highlight below, in the context of utilizing donated gametes and embryos, users of ART not only display an expansive understanding of what constitutes disability and what we are terming diverse normality, but in some instances do appear to choose disability or, at least, to place it on a continuum of normalcy. One of the distinct features of our study is the significance of the contingent and changing context of kin-making within which users of donor gametes are confronting issues of disability and normalcy. The use of genetic testing/screening are practices which typically reinforce and apply a biomedical model of disability in a context of desired family formation using donated gametes. However, these donor gamete practices, protocols, and regulations ignore the contingency of the process of kin-making. Payne notes for instance that the provision of a list of donors to choose from for people undertaking ART appears to 'reinforce the idea that one can choose, and that choosing is unconnected to other social constraints and norms' $(2015,113)$. But she goes on to say that in her study:

while the choice of donor is clearly articulated within a larger discourse of consumer choice also amongst the patients, it does not follow that the patients internalize this discourse in an unequivocal manner. On the contrary, the interviewees have tended either to downplay the process of choosing, stressing to me how "strange" the process of choosing had been or in other ways signalling that they did not regard this process as completely unproblematic (113).

Along similar lines, in a Belgian study, though donor sperm recipients indicated, that familial coherence would be achieved by matching donors with traits that were the same as their own or their partner's personality traits (Raveligian et al. 2014, 9) they also indicated a preference for a donor with whom they had a rapport 'comparable to what you experience when you make a new friend or fall in love with someone' (9). So while users of donated gametes/embryos may initially strive to create sameness or relationships of similarity between themselves and their future progeny when choosing donors, or to eliminate risks of non-normative traits, these desires inevitably bump up against contingent and changing contexts as they engage in their reproductive project of building their families and creating kinship relations. For example, the number of gametes and embryos are limited as are the financial resources to generate additional ones, while in some cases affective relationships between donors and donees become established that displace the importance of sameness or certain traits. Therefore, the contingency of forming kinship is fluid, diverse and complex unlike the fixity and certainty imagined in testing/screening regulations and policies, and this includes the way that disability is received. In their act of forming kinship relationships, often through constrained choices regarding gametes and gamete donors, ART users frequently have to, or choose to, discard biomedical models of disability and employ complex, social, embodied, relational concepts of disability and difference transforming 
disability into a new normal or into something along a continuum of normalcy. Context and contingency are everything in this world of kin-making. As Nordqvist suggests:

The meaning of genes, similarity ... characteristics, aptitudes, physicality ... feelings ...practices, time, fairness and resemblances [and we would add disability] can be renegotiated, revisited and even transformed, and yet still all be used to signal connectedness. Thereby, we can emphasise the importance of some relations whilst discounting others in a way that fits the family we live with and also cope with an unpredictable future (280).

This is in contrast to the knowable future as misleadingly assured by prenatal genetic testing/screening.

\section{Choosing fitness or fitting in}

Despite a proliferation of policy and screening guidelines from clinics, medical professional organisations and regulatory bodies, the four women interviewed in our studies (see below) fashioned their own ideas of what is normal and acceptable, of what kinds of differences make up the categories of disability and diverse normality. What is normal became an idiosyncratic function of an array of factors including: personal desire, emotional connection, qualities of the embryo that are imagined to have a bearing on the future child, gender preference and a variety of embodied characteristics. Normalcy was crafted as a form of relational fitting in to the partially established and imagined future contours of the life or lives of those seeking to procreate.

This decision-making on the part of donor recipients suggests that the views of disability scholars Rosemary Garland-Thomson and Dan Goodley may find some support among our study participants. Both theorists posit normalcy as a potentially ableist concept and argue, instead, for the positive identification of multiple and varying ways of being. Goodley reminds us that 'a whole host of norms ... are, in actuality, limiting and stifling'. Moreover he recognizes the possibility for non-normative 'exciting, radicalizing and alternative practices of everyday life in counterpoint to the idealized normal citizen of our times' (Goodley 2014, 158). Garland-Thomson, utilizes the concept of 'misfit' which she says 'emphasizes the particularity of varying lived embodiments and avoids a theoretical generic disabled body that can dematerialize if social and architectural barriers no longer disable it' (Garland-Thomson, 2011, 592). For Garland-Thomson, disability is not just about functional impairment but rather includes difference that simply does not fit in socially, culturally and materially. She goes on to say:

When we fit harmoniously and properly into the world, we forget the truth of contingency because the world sustains us. When we experience 
misfitting and recognise that disjuncture for its political potential, we expose the relational component and the fragility of fitting. Any of us can fit here today and misfit there tomorrow. (597)

This idea of fit as relational insists on the way that normal/cy exists in the interstices of our agreements about what constitutes it as such. It has no objective status outside of our embodied relations with each other and the institutional and environmental contexts within which we are situated. Misfitting too then is relational. It is not that an individual is inherently 'abnormal' but rather that in a network of relations within a social and material context he or she is out of sync or excluded. The concepts of misfitting and fitting require us, as Garland-Thomson states, to 'recognise that bodies are always situated in and dependent upon environments through which they materialise as fitting and misfitting' (598).

In the context of ART use and choosing donor gametes for the purpose of reproduction, applying the concept of mis/fitting illustrates the contingent, relational and situated character of normalcy that operates in the enterprise of kin making. The misfit is not a particular body (or mind), but the mutually constitutive relationship between a body in its temporal, social and material place - one whose embodiment is out of sync with dominant narratives or norms. Those who use donor gametes and embryos themselves already operate outside of the norm. Reproducing with the use of donor gametes, their practice of technological conception as well as their frequent deviation from the creation of the hetero-normative family marks many ART users as misfits. For others, living with embodied difference marked by society as disability, fuels the desire for progeny created from donor gametes that will better fit in an ableist world. Yet, choosing gamete donors, like choosing kin, is complex. As we illustrate below, a gamete donor may be fit, not because of the anticipated genetic qualities he or she will bestow, but because they fit in with the donor recipient's sense of family. Normalcy, in relation to the choice of donor gametes therefore, is sometimes revealed to be a function not of fitness but of fitting in.

\section{Choosing against, between and within normal}

In this section we offer a carefully selected sample of original data from our ongoing and recent research on assisted reproduction. ${ }^{i}$ We focus on four participants whose unique set of circumstances have required them to make decisions about testing and screening when reproducing with donor gametes or donating embryos that may have a genetic or chromosomal anomaly. We have chosen these four because they demonstrate a range of responses to the idea of normalcy, the subject of this article. Using a semi-structured interview format, participants were asked to reflect upon why they chose to use donor 
gametes or to donate embryos.

The examples we draw on demonstrate how the choices made by our participants trouble assumptions about the meaning of and desire for normalcy in relation to one's future child. Where participants were required to make a decision about disability, our case studies uncover how those decisions are taken both within, and in resistance to, the regime of normalcy prescribed by testing protocols. As our analysis reveals, the process of decision making about the use of donor gametes, for example, suggests a highly textured, contextualized and relational approach. This stands in stark juxtaposition to the apparent normalizing of the decision making process and the standards it is expected that donor recipients follow in making reproductive decisions as demonstrated by the range of testing/screening guidelines, policies and clinic practices. The act of kin making, as the participant interviews we discuss below demonstrate, seem to displace or elide the assumptions about normalcy that are embedded in policy and screening guideline documents. These guidelines are based on a rationalist model that cannot or will not contemplate affect and contingency. In our research however, we see various users fashion their own ideas of normalcy out of the circumstances with which they are confronted, including information about the actual gametes and embryos before them. 'Normal' becomes contingent on what the technology produces - the number, sex, quality of the embryos in relation to the desires and experiences of those using the technologies and the possibly constrained options they have, given their desire to have a baby. Indeed, Nordqvist, in a study of lesbian parenthood using donor conception, suggests that contingency in family creation should be understood as contributing to the construction of kinship. She notes that:

[i]t is important to emphasise that... couples experienced a process which was in part shaped by their desires and wishes, and in part by issues beyond their control. As a result, their routes, wishes and options changed with circumstance and with the way their lives and conception journey 'worked out.' This in turn shaped the way in which they perceived and engaged in the process of bringing kinship into existence. Imagining kinship and the future family was a question revisited again and again with every new avenue explored. (Nordqvist 2013, 271)

While Nordqvist's research does not examine donated gamete users' choices about disability in shaping kinship, it is clear from our research (described below) that a similar process of contingency occurs when gamete users confront decisions of possible or likely difference or disability. Moreover, we found that coming up against the contingency of difference does not always result in the rejection of disability but instead can result in a recalibration of what is normal and what might be considered normal kinship. Our case studies demonstrate what happens when the appearance of choice knocks up against the reality of contingency and how this affects the very conceptualisation of normalcy. Some of our interviewees actively decided against assumed understandings of 'normal' while others found themselves choosing between 
different kinds of 'normal'. Their choices gestured towards the possibility of resisting normative/neoliberal expectations and contributing to the realization of non-normative or diverse normative future possibilities.

Consider Dian,ii who revealed that when choosing an egg donor she went through a complex process that incorporated the donor into the love relationship with her partner. Dian told us:

We spoke to three egg donors. We fell in love with one of them. Then they're about to sign the contract and we realised that this particular donor apparently has - is a Tay-Sachs carrier. Apparently, that can be quite a fatal situation if both - if William [Dian's husband] was also a carrier. I mean it would be fatal. So at that point we cancelled with this particular donor that we'd fallen in love with, and we went on a major search on egg donors. iii So I ended up speaking to about seven egg donors over Skype. Then we didn't find anyone. It's like The Princess and the Pea. Was it The Princess and the Pea? There's a fairy tale like that.

We looked and looked, and there was no-one even close to this particular donor that we really, really fell in love with. William, one day, said 'look, why don't we just consider her again?' So we did, and when we came back we called our agents - the egg donor agency - and said we'd like to go ahead with...

Interviewer: $\quad$ Because you felt so attached to her?

Dian: Yeah, yeah.

Interviewer: So then how did you handle the Tay-Sachs? Did you get William tested?

Dian: Yeah, William was tested. We just thought, well, we don't fall in love with people based on them being perfect, so I guess it - from that point of view. As a result, here she is [the baby].

The language of love and its association with imperfection is interesting because it returns the clinical and contractual context of the use of ART to the motivation for the kinds of choices that are being made in relation to family formation. Here, Dian 
expresses an incapacity for satisfaction in relation to other potential donors in the context of love-expressed through the fairy tale of The Princess and the Pea-a tale which is both about proving the authenticity of Princesshood (here standing in for motherhood) and the appropriate object of love for the Prince. In our case however, it is the authenticity of the donor as the appropriate object of love for Dian and William, the intending parents, that is established.iv. Dian makes the egg donor the recipient of love and as such normalises her genetic status - 'we don't fall in love with people based on them being perfect'. In this sense Dian is prepared to accept the donor's carrier status even though it may be passed on to the future child.v The development of this love relationship stands in contrast to the moral framework that typically animates bioethicists. They argue that there is a

morally relevant difference between donor conception and reproduction between partners. Partners want to reproduce together, whereas people needing donor gametes do not (in most cases) want to reproduce only with this donor. And whereas partners cannot be replaced, donors, as providers of gametes are replaceable. (Dondorp et al. 2014, 4)

In Dian's case the fungibility of donors was absent because of the way she constructed her relationship to the donor inside the love relationship that originally motivated reproduction in the first place. For Goodley, desire is a force through which we connect with one another' (165) and disability studies invites us to rethink how and what we desire as we use technological means to create new forms of kin and relationality. Dian's experience with her donor exemplifies the possibility of desiring new non-normative becomings and belongings.

In a second example, Olivia, who initially attempted to use her own eggs but was unsuccessful, was the recipient of both donor oocytes and sperm. Olivia decided to use sex selection because she did not want to have a boy and risk the possibility of having an autistic child.vi Olivia's brother had two sons she described as "borderline autistic but highly ADHD". Olivia sought out an American clinic where she could have genetic testing. By day six when Olivia attended the clinic for the transfer she had six healthy male embryos, one female embryo that tested positive for trisomy 21 (Down syndrome) and four embryos of unknown sex that had been sent for testing without results. Keen to have a girl, she chose not to have one of the six known 'healthy' male embryos transferred but rather to have two of the untested embryos transferred. She did not contemplate transferring the only identified female embryo which she described as 'abnormal'. She went on:

Olivia: Yes, and so I elected to have transfer of two of the four unknown sex embryos.

Interviewer: $\quad$ Oh okay.... 
Olivia: Yeah, because they explained to me that if they were abnormal they would not likely work and there was, obviously in my mind there was a higher chance that one of the embryos - because I had two transferred - that one of them or two of them maybe might be female, versus knowing that the other ones are all male. So I received the results the following day and it turned out that the two that they transferred were both healthy male embryos [laughs] and the other two that they didn't transfer were abnormal.

So at that point I spent the following two weeks coming to terms with it and decided that I really wanted a healthy baby more than I wanted a daughter and that having a family is more important to me than anything.

As noted above these kinds of choices and decisions are made in embedded and contingent contexts. In Olivia's case her relationship to her brother and his children had initially driven her quest for a girl. But, her desire for a girl, once established as a choice she might make, appears to have cemented as separate from any disability avoidance strategy. Once, however, that choice bumps up against the contingency and context of her own reproductive options she reframes her desire and normalizes her disappointment. This is evidenced in her interview when Olivia speaks about reading internet forums on 'gender disappointment'. She says:

There's actually a lot of information about gender disappointment online and so I've read a lot of people's stories and realised that it is unrealistic to expect that you can get what you want all of the time [laughs].

Much later on she says:

It just emotionally helps you to deal with it all the way through because you're able to then say okay, well there was a girl but it wasn't a healthy embryo. 
Goodley argues that ' $[\mathrm{t}]$ he normal category exists not as a simple fixed position of humanity but as a register, a subject position, a preferred way of living life and a phenomenon of ableist cultures' (118). Thus while this example might seem more appropriately placed in an article discussing the ethics of gender selection we have included it here because as Goodley notes 'normals' are each marked by differences associated with gender, class, sexuality, age and ethnicity (118). Therefore though we might accept that '[b]eing normal is one of society's preferred ontological states and moral categories,'(118) we argue that the category of normal is a shifting and flexible signifier. Olivia's imagining of gender disappointment then substantiates Goodley's point that neither normalcy nor disability are simply about having an embodied difference but are inflected by social and cultural readings of difference including how they are gendered.

In contrast to Olivia, Cybil, an interviewee who diagnosed herself with Aspergers, and believes her son born through traditional surrogacy [where the surrogate is also the egg donor] has autism spectrum disorder made it clear that the possibility of ASD from her egg donor was not something that raised concerns. Asked about the kinds of information she received about the medical history of her donor she replies:

Cybil: I think family history of cancer and heart disease, stroke, diabetes and whatever, but either positive or negative. Emmeline [the egg donor and surrogate] disclosed that she had ADHD and there was a history of autism in her family, which we are now seeing probably in Louie.[Cybil's son] He's getting ready to do his ASD assessment.

Interviewer: Okay, so is that Autism Spectrum Disorder?

Cybil: Yeah.

$\cdots$

Interviewer: $\quad$ Okay ...it sounds like it was an expectation that it was not unlikely? 
Cybil: Yeah, it was not unlikely and it was a risk we took, so okay, well he could have a chance of having anything. Probably the thing that I was most apprehensive about was if it had a genetic disorder that was compatible with life such as Down syndrome or anything else, ... It's hard to know really at the end of the day, but we were pretty convinced that we really didn't want to have a special needs child, because we didn't have any energy left after the end of the whole process that we'd gone through.

Referring to the surrogate, Cybil indicates that she would not have agreed to an abortion and says: 'so we had to roll that dice and it was very nerve-wracking. It was like well, we either choose to take this risk or we don't become parents'. Asked whether she viewed this decision as hard Cybil replies: 'It was just one after the other of massive compromise and letting your values go so that you could get to the end of the journey'. Again we see a clear sense in which desires bump up against contingency and normalcy is reformulated accordingly. Indeed, we see an interesting disconnect between contemporary medical approaches to disability and that of the intending parent. Whereas clinics view their role as limiting the risk of disability, the intending parent appears prepared 'to roll the dice' and deal with contingency.

In this case Cybil viewed ASD as a risk to be taken compared with Down syndrome. This bears out our argument that ideas of normalcy are shifting and flexible and circulate around familial fitting in.. Rather than trying to achieve a child with no disabilities or genetic conditions recipients are interested in family coherence and appear to determine normalcy relationally. In Cybil's case Autism didn't challenge that coherence but Down syndrome did.

This notion is also borne out in the experience of Scarlet (a donor, rather than a donor recipient).vii She was denied the ability to donate her embryos because they were determined to be genetically affected. Scarlet's genetic condition had a 100 percent transmission rate, but she had identified potential recipients for her embryos who were aware of her genetic condition and wished to receive the embryos notwithstanding. The clinic however, refused to facilitate the transfer on the basis that it was not in the best interests of the resulting children. Scarlet then put her case (unsuccessfully) before the ethics committee of her clinic. In her interview she remarked on how confronting it was to be told what amounted to the view that it was not in the best interests of her own children who bore the same condition and were conceived at the same time as the embryos she was seeking to donate, to be born. She said:

my children are immensely loved and showered with everything they need and they're well built up, well cared for and it's hard to say that it was not in their best interests to even exist. 
Scarlet's experience, and that of the potential recipients who wanted to transfer her donated embryos, illustrate starkly Davis's argument that disability occupies the 'state of exception'(8) in a regime of normalcy, here enforced by an infertility industry and bioethics regime. But where Davis argues that in conditions of normality construed as diversity, disability falls outside choice (14) and is not chooseable (11), the story of Scarlet suggests otherwise, at least from the point of view of prospective users of ART and recipients of donor gametes and embryos. While Scarlet's aim of donating has been thwarted by ableist policies and practices, by a misfit between the social and cultural devaluation of those who share Scarlet's characteristics and their reproductive aspirations, her expressed desire and that of her potential donor recipients to reproduce that which others regard as unfit to come into being, indicate an active embracing of disability - what we would call diverse normalcy from the point of view of Scarlet and her potential recipients. But what this example makes urgently apparent as well, is that being able to choose against idealized normalcy and embrace diverse normalcy in the creation of one's family, to give material effect to one's choices, is unsurprisingly, contingent and thoroughly political - like the concept of normalcy itself.

\section{Conclusion: who decides who fits?}

The idea of the 'normal,' as we have stated in this article, is both a descriptive and prescriptive concept. The prescriptive element in particular is contingent on scientific data coupled with social and cultural explanations to define its content. It follows that the normal is also understood as one side of an oppositional binary, in contrast to the 'abnormal' or disability (Goodley 2014) or, as Davis would state, disability is the exception to the norm of diversity. Thus, normalcy and abnormalcy/disability exist in a relationship of co-constitution. This is not to suggest a permanence to their respective content, but to propose that constructions of normalcy are generally thought to exist against that which an (inferior) Other (disabled/abnormal) is conceptualized. (Goodley 2014, 88).

While agreeing with much of this understanding of normalcy and its relationship to abnormalcy and disability, in this article we have offered a more textured and contextual account building on the specific perspectives of interview subjects engaged in choosing gametes or embryos for reproductive purposes. Employing the concept of diverse normality we demonstrate how, in the constrained and contingent context of selecting gamete and embryo donors, some recipients deploy an expansive conception of normalcy, making a reproductive choice that would not otherwise have been contemplated. Moreover, as we have argued, in the context of choosing donor gametes or embryos for purposes of ART, what is normal for some recipients may rely less on 
assumptions about what it is to be healthy or fit and indeed more on what it means to 'fit in'. Yet for others, the contours of diverse normalcy include an active embracing of disability, apparently breaking down the binary altogether. Garland-Thomson states that 'to fit and be fit, ... is to be ensconced in an environment that sustains the particular form, function and needs of one's body'. (600) It is clear from our research that for some people fitting in - being normal - is enhanced or delimited not by difference or deviation from some external standard of what is good and right but by love and desire and a matrix of relationships.

\section{Notes}

i The larger project is with Professors Millbank, Stuhmcke and Jackson (ARC DP 15010157: Regulating Relations). We refer briefly to earlier research Karpin conducted with Professors Millbank and Stuhmcke (DP ARC DP 986213: Enhancing Reproductive Opportunity). Ethics approval was granted by the University of Technology Human Research Ethics Committee for both projects.

ii All interviews use pseudonyms to preserve anonymity and confidentiality:

iii It is worth noting here that the decision to find an unaffected donor is based on the view that donors, unlike intimate partners are fungible and therefore even carrier status is to be avoided. See Dondorp_2014.

iv Notably Dian knows the donor only through her communications with her on Yahoo and there are no names exchanged. She is both unknown and known and yet the relationship is characterised in terms of love.

v While William's test for Tay Sachs is negative, there is still a 25 percent possibility that Dian and William's child will be a carrier of Tay Sachs because the egg donor was a Tay Sachs carrier and the condition is autosomal recessive.

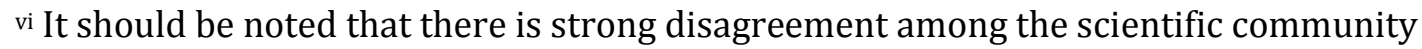
regarding the association of ASD and maleness. See Karpin, I. 2015.

vii Scarlet was participant interviewed for the Enhancing Reproductive Opportunity study that preceded the study in which our other case studies were interviewed. Further details of the earlier research can be found in a special issue of the Journal of Law and Medicine Volume 20(4). See specifically Millbank, Jenni. et al._2013. See also Millbank, Jenni (forthcoming). 


\section{References}

ARC DP: Regulating Relations: Forming Families Inside and Outside Laws Reach. (ARC DP 15010157 Chief Investigators: Professors Jenni Millbank, Isabel Karpin, Anita Stuhmcke (UTS); Partner Investigators: Professors Emily Jackson (LSE) and Roxanne Mykitiuk (Osgoode Hall)) HRC approval UTS reference no. 2015000094.

ARC DP: Enhancing Reproductive Opportunity (ARC DP0986213 Chief Investigators: Professors Jenni Millbank, Anita Stuhmcke, and Isabel Karpin (UTS)) ACOG (American Congress of Obstetricians and Gynecologists). 2011. Committee Opinion No. 486: update on carrier screening for cystic fibrosis. Obstetrics \& Gynecology 117 (4):1028-1031. doi: 10.1097/AOG.0b013e31821922c2. Commission Directive 2006/17/EC of 8 February 2006 implementing Directive 2004/23/EC of the European Parliament and of the Council as regards certain technical requirements for the donation, procurement and testing of human tissues and cells, Annex III, 3.6. http://eur-lex.europa.eu/eli/dir/2006/17/oj. Daniels, Cynthia R. and Erin Heidt-Forsythe. 2012. "Gendered Eugenics and the Probelmatic of Free Market Reproductive Technologies: Sperm and Egg Donation in the United States." Signs 37 (3): 719-747.

Davis, Lennard J. 2013. The End of Normal - Identity in a Biocultural Era. Ann Arbour: University of Michigan Press.

W. Dondorp, G. De Wert, G. Pennings, F. Shenfield, P. Devroey, B. Tarlatzis, P. Barri, K. Diedrich, U. Eichenlaub-Ritter, F. Frank Tüttelmann, and V. Provoost. , 2014. "ESHRE Task Force on Ethics and Law 21: genetic screening of gamete donors: ethical issues." Human Reproduction 29 (7): 1353-1359. doi: 10.1093/humrep/deu111.

Garland_Thomson, Rosemarie. 2011. "Misfits: A Feminist Materialist Disability Concept.” Hypatia 26 (3): 591-609.

Ginsburg, Faye and Rayna Rapp. 2015. "Making Disability Count: Demography, Futurity, and the Making of Disability Publics." Somatosphere, May 11. http://somatosphere.net/?p=10236.

Goodley, Dan. 2014. Dis/ability Studies - Theorising Disablism and Ableism. London: Routledge. 
Karpin, I. 2015. "The Regulation of PGD for Medical Sex Selection and the gendering of disability in the UK and Australia." In Revisiting the Regulation of Human Fertilisation and Embryology, edited by K. Horsey, 185-199. London: Routledge.

McGowan, Michelle L., Deborah Cho, and Richard R. Sharp. 2013. “The Changing Landscape of Carrier Screening: Expanding Technology and Options?" Health Matrix Clevel 23 (1): 15-33.

Millbank, Jenni, Eloise Chandler, Isabel Karpin and Anita Stuhmcke. 2013. “Embryo Donation for Reproductive Use in Australia." Journal of Law and Medicine 20 (4): 789-810.

\section{Millbank, Jenni "Reflecting the "Human Nature" of IVF Embryos: Disappearing}

\section{Women in Ethics, Law and Fertility Practice." Journal of Law and the Biosciences (forthcoming)}

Nordqvist, Petra. 2014. “Bringing Kinship into Being: Connectedness, Donor Conception and Lesbian Parenthood." Sociology 48 (2): 268-283.

Payne, Jenny Gunnarsson. 2015. "Reproduction in transition: cross-border egg donation, biodesirability and new reproductive subjectivities on the European fertility market." Gender Place and Culture 22 (1): 107-122.

Ravelingiena, A., V. Provoosta, E. Wyverkensb, A. Buysseb, P. De Sutterc, and G. Penningsa. 2014. "Lesbian couples' views about and experiences of not being able to choose their sperm donor." Culture, Health \& Sexuality: An International Journal for Research, Intervention and Care 17 (5): 592-606. doi: 10.1080/13691058.2014.979883.

Reh, Andrea, Alana Amarosa, Frederick Licciardi, Lewis Krey, Alan S. Berkeley, and Lisa Kump. 2010. "Evaluating the necessity of universal screening of prospective oocyte donors using enhanced genetic and psychological testing." Human Reproduction 25 (9): 2290-2304.

Taylor, K., and R. Mykitiuk. 2001. “Genetics, Normalcy and Disability.” ISUMA: Canadian Journal of Policy Research/Revue canadienne de recherche sur les politiques 2 (3): 65-71.

Wienke, Sara, Kimberly Brown, Meagan Farmer, and Charlie Strange. 2014. "Expanded carrier screening panels - does bigger mean better?" Journal of Community Genetics 5 (2): 191-198. 